\title{
Extracurricular Activities at Modern Russian University: Student and Faculty Views
}

\author{
Galina P. Ivanova ${ }^{1}$, Olga K. Logvinova ${ }^{1 *}$ \\ ${ }^{1}$ Department of Psychology and Pedagogy, Philological Faculty, RUDN University, Moscow, RUSSIA
}

Received 24 April 2017 - Revised 26 August 2017 • Accepted 28 September 2017

\begin{abstract}
This article deals with the problem of arranging extracurricular activities for students at a modern Russian university. Research interest in this issue stems from the fact that extracurricular activities are of great concern in the development of modern students' professionally important qualities and their professional competence. There is a critical need to change the approaches to the organization of extracurricular activities at a university in the light of modern tendencies of higher education development and the opinion of faculty and student community. The authors focus on students' and faculty members' views and expectations of extracurricular activity. The research identified priority tasks of extracurricular activities. The recommendations on the organization of extracurricular activities at the level of the chair (department) were developed. The necessity of searching for a flexible, adaptive model of extracurricular activities at the university level is substantiated considering the specifics of the educational environment of a particular university; promising directions for further research are determined.
\end{abstract}

Keywords: extracurricular activities, modern university, professional orientation, faculty members, university students

\section{INTRODUCTION}

The mission of a modern university is not limited to the training of highly qualified professionals. Today, the universities face the task of forming a personality that possesses general cultural competences, value system, the capacity for self-development and self-improvement. The use of the potential of extracurricular activities aimed at overcoming pragmatism in education and creating optimal conditions for the harmonious development of students capable of creativity, self-determination, and self-realization in a rapidly changing world is being actualized. Extracurricular activities are of special importance in internationally oriented universities, in the context of a multinational and multi-cultural educational environment where the socio-cultural adaptation of foreign students is an important component.

The Peoples' Friendship University of Russia (RUDN University) is one of the largest and the most multinational university in the country. Currently, more than 30 thousand students from 154 countries of the world are studying at the university. Traditionally, RUDN University has paid special attention to student life, extracurricular activities, an important part of which is amateur student creativity in national and international groups. Since the foundation of the university, extracurricular activities have contributed to the creation of a unique multi-national and multi-cultural environment built on the principles of tolerance and mutual respect. At the same time, nowadays, there is a need to change the approaches to the organization of extracurricular activities at the university, taking into account the current realities and trends in the development of higher education, and the ever increasing ethnic and social diversification of the student fraternities. It is becoming urgent to search for the types and forms of extracurricular activities that are adequate to the requirements of the time and expectations of the modern generation of students.

In this regard, the goal of this research is to identify the priority tasks of extracurricular activities at a modern university, the main directions and types of extracurricular activities, to study the subjective attitude of students, 


\section{Contribution of this paper to the literature}

- The priority tasks of extracurricular activities at a modern university are determined.

- The contradictions between the official tasks of extracurricular activities proclaimed at the university level, and the needs of current generation of students, as well as the faculty capabilities have been revealed.

- The author's model for organization of extracurricular activities at the chair/department level has been developed.

post-graduate students and faculty members to extracurricular activities in general and to the process of its implementation at the university, to develop a model for organization of extracurricular activities at the level of the chair (department). The hypothesis is that there are certain differences in the views of participants in the educational process on extracurricular activities, their tasks and functions; not all types of extracurricular activities implemented at the university correspond to the interests and value orientations of the current generation of students.

\section{LITERATURE REVIEW}

In modern Russian and foreign literature on pedagogy/education, the problem of extracurricular activities at the university is widely discussed.

The results of the research analysis indicate that there is no generally-accepted definition of this phenomenon (Bartkus et al., 2012; Gismatullina, 2012). American researcher Kenneth R. Bartkus and his colleagues characterize extracurricular activities as "academic or non-academic activities that are conducted under the auspices of the school but occur outside of the normal classroom time and are not part of the curriculum" (Bartkus et al., 2012: 698). The authors emphasize that extracurricular activities do not involve a grade or academic credit and participation is optional on the part of the student. This definition describes exactly the essence of extracurricular activity at the modern university.

The analysis of Russian pedagogical literature makes it possible to consider extracurricular activities at a university as a set of interrelated but different types of activities aimed at the all-round development of the student's personality and the formation of professional qualities of the future specialist. This includes the formation of social activity - the integrative quality of the personality, manifested in the initiative social activity, conditioned by the internal and external activity of the individual, in the transformation of oneself and the surrounding reality in accordance with the norms and values accepted in a society (Shakirova, 2008).

In Russian studies, much attention is paid to the educational and upbringing function of extracurricular activities. Extracurricular activities are considered to be a significant factor in the formation of general cultural and professional competences, the development of the personality of the student (Vintin 2016; Alieva et al., 2014; Rudenko \& Alieva, 2011). Extracurricular activity is even thought of as one of the sources of the university's competitive growth in the age of internationalization of higher education (Gismatullina, 2012, 2013).

Foreign scholars more often address the problem of the impact of extracurricular activities on the academic performance of students. At present, serious qualitative and quantitative research has been carried out, and a positive connection between the level of academic achievement and the involvement of the student in extracurricular activities has been concluded (Bakoban \& Aljarallah, 2015; Zacherman \& Foubert, 2014; Strapp \& Farr, 2010). The influence of extracurricular activities on the ability to find employment and professional adaptability (extracurricular short- and long-term effects on employability) is analyzed in Clark et al., 2015.

A number of Russian and foreign publications discuss the role of extracurricular activities in the process of multi-cultural education, the development of the ability to intercultural interaction in future specialists, and tolerant perception of social and cultural differences (Cheng \& Zhao, 2006; Musaev, 2014; Logvinova, 2016). Thus, David Cheng and Chun Mei Zhao show the remarkable positive effect of extracurricular activities on multi-cultural learning (Cheng \& Zhao, 2006).

Nevertheless, in scientific literature, insufficient attention is paid to the attitudes of modern students toward extracurricular activities, their expectations; and the problem of faculty readiness to participate in the organization of extracurricular activities at a university is practically not discussed.

\section{MATERIALS AND METHODS}

In the process of research, a set of theoretical and empirical methods were used. A comparative analysis of normative documents defining priority directions and tasks of extracurricular activities at the university was carried out. The method of theoretical modeling was applied. In the course of empirical research, both quantitative 
and qualitative methods were used; in particular, the focus group method. In total, 4 focus groups were formed: bachelor students (10 participants), master students (10 participants), postgraduate students (10 participants), and teachers (8 participants).

Also, the authors' standardized questionnaire was used to determine the sex-age composition of the sample, the level of respondents' education, as well as the level of respondents' involvement in extracurricular activities and their positions within the studied problem. The survey involved 260 respondents - students and teachers of the Faculty of Philology. The results of the survey of 15 respondents were not taken into account in connection with the risk of random responses and incorrect filling in of questionnaires. Responses of 245 respondents were taken into account, including 95 bachelor students, 122 master and postgraduate students, and 28 university teachers. The students doing master and postgraduate courses were united into one group of respondents on the basis of common characteristics (average age, experience of participation in extracurricular activities at the university, combining educational and professional activities, priority of research work). The average age of bachelor students was 19 years, master and postgraduate students were aged 25 and teachers were 40 years old on average.

Two groups were compared by the quantitative scale on the basis of the nonparametric Mann-Whitney criterion. Comparisons of three groups by the quantitative scale were carried out on the basis of the nonparametric KruskalWallis criterion. Statistical significance of different values for binary indicators was determined using the Chisquare test. To describe the quantitative indicators, the mean value and standard deviation in the " $M \pm S^{\prime \prime}$ format were used. The level of statistical significance was fixed at the error probability level of 0.05 . Statistical processing of data was performed using the Statistica 10 and SAS, JMP 11 application packages.

\section{RESULTS}

The analysis of regulatory legal documents and real educational practice has shown that extracurricular activities act as an independent function of higher education, and consist of three components: extracurricular activities of students, extracurricular work of faculty and staff with students, and a system for managing extracurricular activities.

Based on the analysis of ruling documents, it seems possible to single out the following priority tasks of extracurricular activities at the present stage:

- forming high culture in students, including in the field of inter-ethnic communication;

- forming respectful and careful attitude to the historical heritage and cultural traditions of countries and peoples;

- forming active citizenship, social activity of the individual and educating for patriotism;

- forming a worldview aimed at internationally oriented creative activity;

- forming a corporate culture, respect and preservation of the university's traditions;

- forming aspiration to self-development, creativity, ability to social and professional adaptation in changing conditions;

- forming the value of a healthy lifestyle.

The conducted empirical research has allowed revealing a number of contradictions and urgent problems in the organization of extracurricular activities.

$96 \%$ of the bachelor students surveyed, $97.5 \%$ of master and postgraduate students and $100 \%$ of university teachers agreed with the statement that extracurricular activities are an integral part of the educational process at the university and should be implemented on the basis of voluntary and free choice of students. Only $4 \%$ of the bachelor students surveyed and $2.5 \%$ of post-graduate and master students share the viewpoint that extracurricular activities should not be given much attention at the university, since the main thing is educational activity and scientific research.

These results were analyzed and clarified during the work with the focus groups. The participants showed a conscious attitude to extracurricular activities, cited arguments that confirm its significance. Only one female bachelor student (19 years old) denied the need for extracurricular activities at a modern university, emphasizing that young people come to the university to get knowledge and all the time should be devoted exactly to academic activity.

The majority of respondents sometimes take part in extracurricular activities at the university $(71.6 \%$ of bachelors, $60.7 \%$ of faculty, and $52.9 \%$ of post-graduate students). Frequent participation is noted in $28.6 \%$ of faculty, $13.7 \%$ of bachelor students and $16.5 \%$ of master and post-graduate students. At the same time, $30.6 \%$ of post-graduate and master students, $14.7 \%$ of bachelor students and $10.7 \%$ of faculty do not participate in extracurricular activities. 


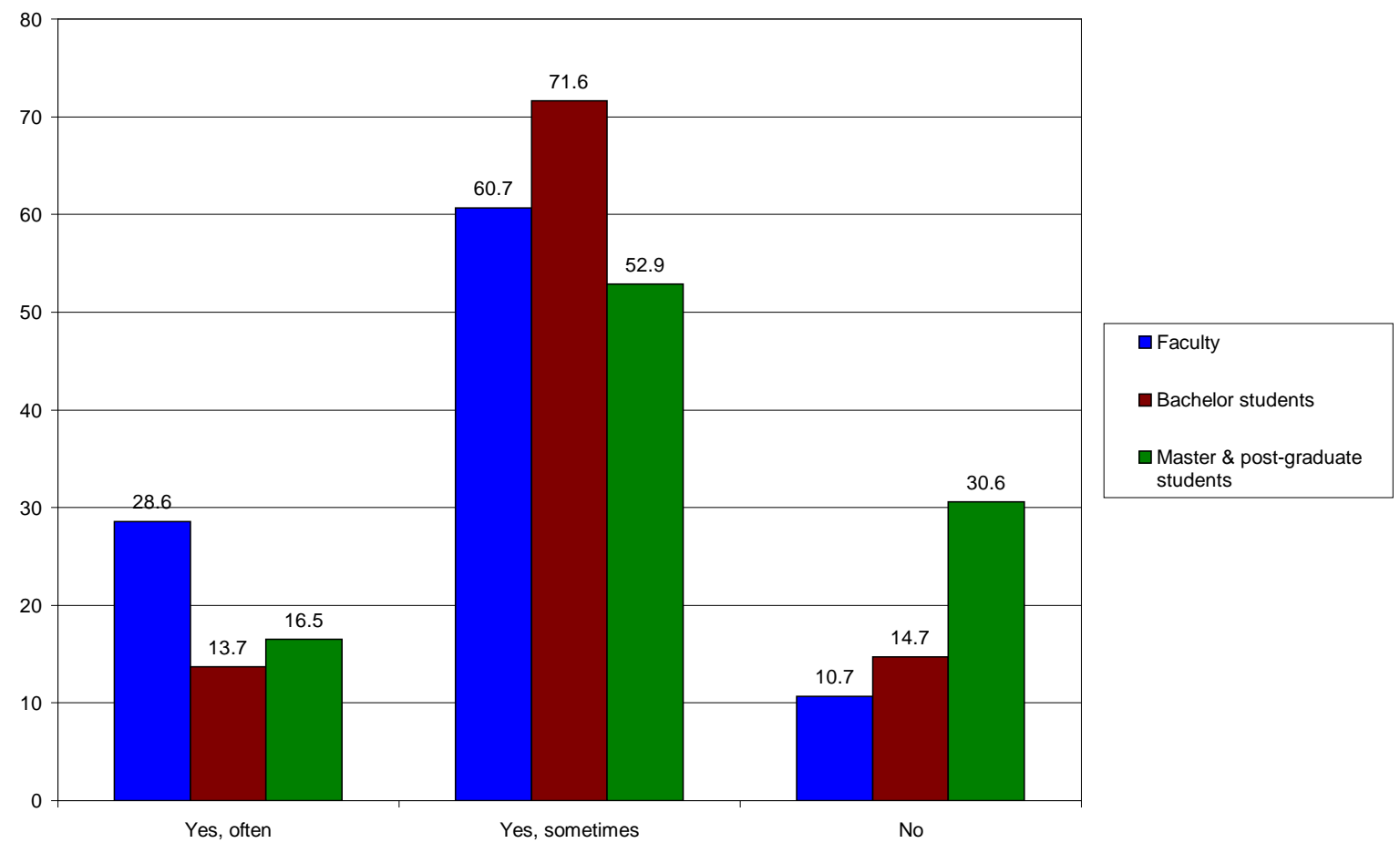

Figure 1. Participation in extracurricular activities

Within the focus groups, the reasons for the rare participation/non-participation in extracurricular activities were discussed. Students noted the need to combine study at a university and work and, as a result, lack of free time as the main reason. Another common reason was insufficient information coverage. Despite the availability of information on the official websites of the university and faculties, special announcement boards, students do not always know about upcoming events in a timely manner. Participants in the focus groups, expressing the opinion of the majority of students, said that the information should be targeted, sent to the students' personal email, or communicated directly in the classrooms.

The major part of bachelor students $(54.7 \%)$ and $32.1 \%$ of faculty are ready to organize extracurricular activities on their own initiative, $25 \%$ of university teachers, $21 \%$ of bachelor students and $20.5 \%$ of master and post-graduate students are ready to be occupied only on the instructions of the university head/administration. And 10.7\% of faculty, $24.2 \%$ of bachelor students and $20.5 \%$ of master and post-graduate students are not ready to engage in the organization of extracurricular activities. 


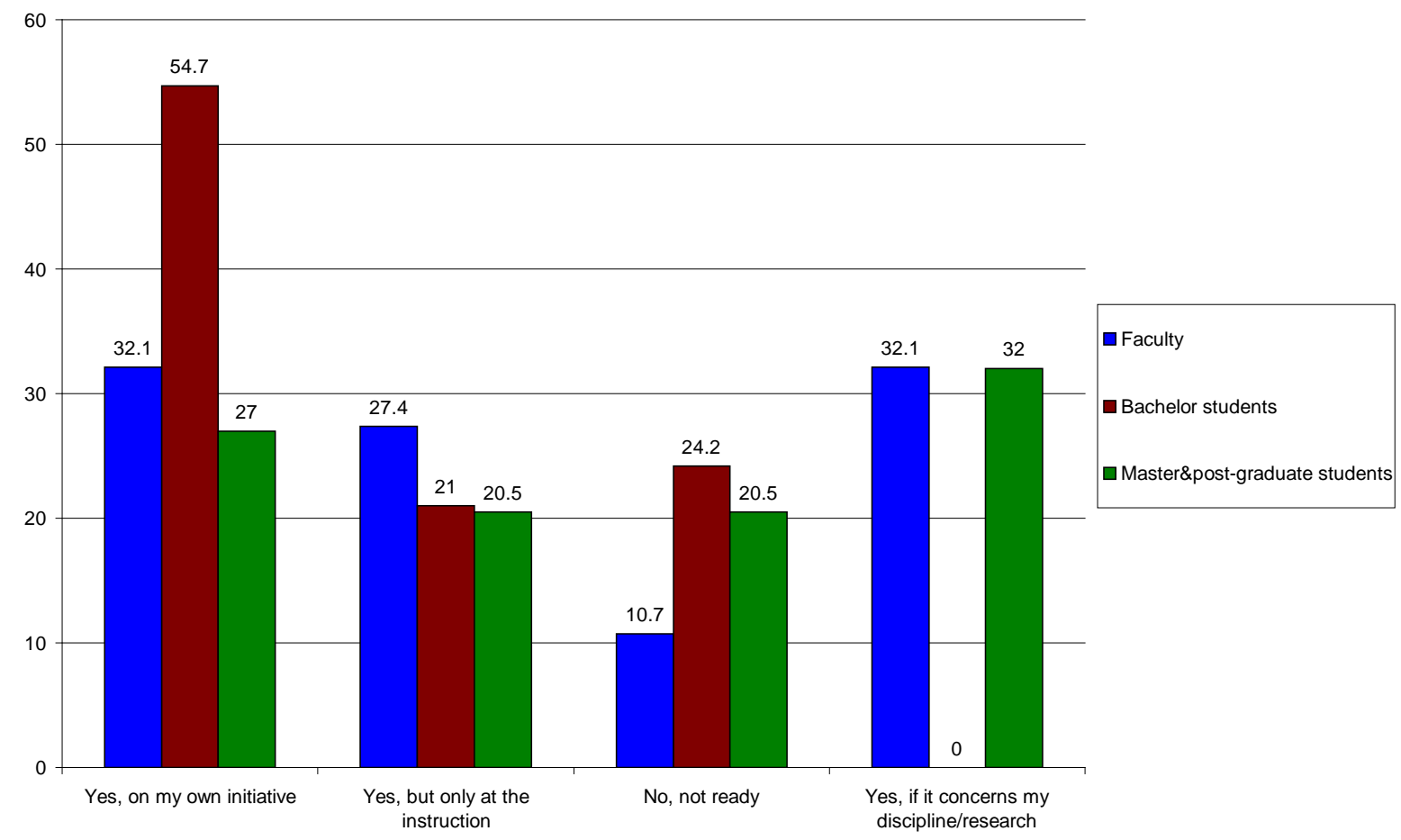

Figure 2. Readiness to engage in the organization of extracurricular activities

Table 1. University teachers' readiness to engage in the organization of extracurricular activities

\begin{tabular}{lc}
\hline Readiness to engage in the organization of extracurricular activities & Faculty members, (N=28) \\
\hline Yes, on their own initiative & $9(32.1 \%)$ \\
\hline Yes, but only within the framework of the discipline taught & $9(32.1 \%)$ \\
\hline Yes, but only on the instructions of the university management & $7(25 \%)$ \\
\hline No & $3(10.7 \%)$ \\
\hline
\end{tabular}

Out of the 28 participants in the survey, 9 university teachers (32.1\%) underlined that they are ready to engage in extracurricular activities only if it is directly related to the discipline taught (Table 1).

Faculty in the focus group defended the idea that extracurricular activities carried out at the departments should be aimed at the professional orientation of students, the solution of the task of professional upbringing, in the process of which values, norms, rules specific to a certain professional culture are appropriated, and a stable model of professional behavior of future specialists is formed.

At the same time, as the study has shown, career guidance activities for bachelor students are not the most needed.

Table 2 shows the average rating for all types of extracurricular activities for each status from 1 to 9 (from the most significant type to the least significant). The ratings of faculty and master and post-graduate students are close; they consider career-oriented activities, cultural and educational activities, fitness and sports activities to be the most important types of extracurricular activities for students, and work activities and mass cultural events to be less significant. For bachelor students, the rating according to the importance of activities is different. In their understanding, mass cultural events are the most significant for the students, they are followed by career orientation activities and creative activity, and competitive events and fitness and sports activities are less important. 
Table 2. Comparison of statuses by indicators of the significance for the types of extracurricular activities

\begin{tabular}{|c|c|c|c|c|c|c|c|}
\hline \multirow[t]{2}{*}{ Indicator } & \multicolumn{2}{|c|}{$\begin{array}{l}\text { Faculty } \\
(\mathrm{N}=28)\end{array}$} & \multicolumn{2}{|c|}{$\begin{array}{l}\text { Bachelor students } \\
\qquad(\mathrm{N}=95)\end{array}$} & \multicolumn{2}{|c|}{$\begin{array}{c}\text { Master and post-graduate } \\
\text { students }(\mathrm{N}=122)\end{array}$} & \multirow[t]{2}{*}{ Level $\mathbf{P}$} \\
\hline & $M \pm S$ & rating & $M \pm S$ & rating & $M \pm S$ & rating & \\
\hline $\begin{array}{l}\text { Mass cultural events (festivals, } \\
\text { concerts etc.) }\end{array}$ & $5.3 \pm 1.9$ & 8 & $3.4 \pm 2.1$ & 2 & $5.1 \pm 1.9$ & 8 & $<0.0001$ \\
\hline $\begin{array}{l}\text { Cultural and educational } \\
\text { activities (excursions, etc.) }\end{array}$ & $3.1 \pm 1.8$ & 2 & $4.4 \pm 2.2$ & 6 & $3.6 \pm 2.2$ & 3 & 0.0108 \\
\hline Creative activity & $4.9 \pm 2.1$ & 6 & $4.1 \pm 2.2$ & 4 & $5 \pm 1.8$ & 7 & 0.0027 \\
\hline Fitness and sports activities & $4.4 \pm 1.8$ & 3 & $4.8 \pm 2.3$ & 8 & $4.5 \pm 2$ & 4 & 0.2554 \\
\hline Competitive events & $5.2 \pm 1.9$ & 7 & $4.8 \pm 1.9$ & 7 & $4.5 \pm 2.1$ & 5 & 0.3939 \\
\hline Volunteering & $4.5 \pm 2$ & 5 & $4.3 \pm 2.2$ & 5 & $4.6 \pm 2.1$ & 6 & 0.2963 \\
\hline Career guidance events & $2.3 \pm 2.1$ & 1 & $4 \pm 2.6$ & 3 & $2.7 \pm 2.3$ & 2 & 0.0001 \\
\hline $\begin{array}{l}\text { Labour activities (student } \\
\text { construction brigade, etc.) }\end{array}$ & $5.3 \pm 2.3$ & 9 & $5.8 \pm 2.5$ & 9 & $6.1 \pm 2.3$ & 9 & 0.2429 \\
\hline Other & $4.5 \pm 3.5$ & 4 & $2 \pm 0$ & 1 & $2.5 \pm 1.2$ & 1 & 0.5548 \\
\hline
\end{tabular}

During the discussion, focus groups identified certain differences in the views of bachelor and master/postgraduate students. Bachelor students prefer those types of extracurricular activities that enable creative selfactualization and informal communication; they are interested in festivals, creative events, such as, for example, the Miss Philological Faculty. Widespread open lectures on various topical issues were evaluated negatively by the majority of participants in the focus group; bachelor students are ready to attend them only as part of the educational process, but not in their spare time.

Master/post-graduate students, like faculty members, noted the priority of those types of extracurricular activities, which, in one way or another, are related to professional orientation or scientific research.

From the point of view of the majority of respondents, volunteering and labor activities are not a priority for modern students (see Table 2).

All the participants of focus groups agreed with the statement that the modern generation of students prefer interactive forms of events; they are not interested in being just spectators or listeners. Psychological trainings, business games, master classes of highly qualified specialists are in demand.

\section{DISCUSSIONS}

The conducted research allows singling out a number of contradictions between the official tasks of extracurricular activities proclaimed at the university level and the needs of the modern generation of students as well as the faculty capabilities.

The administration of the university pays much attention to activating the extracurricular work of the structural units, primarily the chairs and departments. Every year, the university holds a contest among the chairs (departments), faculties and institutes for the best organization of extracurricular work with students. Indicators such as the organization and development of student associations, holding extra-curricular events (excursions, contests, lectures, round tables, concerts, etc.), preservation of traditions and the introduction of innovations in the organization of extracurricular activities, information activities and ensuring regular interaction with students through the Internet communities are important criteria for evaluating the activities of chairs/departments.

When planning extracurricular activities, each chair/department, first of all, is guided by the directives of the university or faculty administration. However, the effectiveness of the extracurricular work of the departments and the university as a whole primarily depends on whether the interests and expectations of students and faculty are taken into account, whether the choice of content, forms, methods of extracurricular activities are made with regard to their opinion. As shown by the conducted research, the students' views do not always coincide with the opinion of university teachers and the expectations of the administration.

Attention is drawn to the fact that more than $50 \%$ of bachelor students are willing to take the initiative and organize extracurricular activities. During the discussion of the problem in focus groups, bachelor students noted that, despite the desire and certain abilities, not everyone is ready to take the initiative. Among the reasons there were the following: "I'm afraid to look like an upstart", "I do not want to stand out in my group", "I'm afraid that the administration/faculty will not approve my idea", "I cannot put together a team of like-minded people on my own", and so on.

At the same time, personal fulfilment of student youth, stimulation and systematical support of the initiative can significantly improve the quality of extracurricular activities and reduce the additional burden on the faculty members. 
Extracurricular work is a part of faculty official functions, but it is usually carried out within the framework of the taught disciplines or scientific activity. For example, it is traditional for the teachers of the department of psychology and pedagogy to arrange excursions to the Moscow Museum of Education named after Academician G. A. Yagodin, the Center for Emergency Psychological Aid of the EMERCOM of Russia, the Scientific and Educational Center "Experimental Psychology", during which students become acquainted with the specifics of psychological and pedagogical activity, get the opportunity to communicate with highly qualified specialists directly in a professional environment.

Currently it is not possible to demand from the university teacher active participation in the organization of various types of extracurricular activities that are not directly related to the sphere of their professional and scientific interests, as well as the fulfillment of high indicators of scientific research work and a significantly increased classroom work simultaneously. This makes it necessary to search for additional internal resources that would allow full-scale implementation of extracurricular activities in all areas in demand. In this connection, tutoring activities possess significant potential. Two complementary models of tutoring are realized in the RUDN University: the tutor for academic work, who plays an essential role in the system of ensuring the quality of education at the faculty, and the tutor for upbringing/educational work, who provides social, psychological and pedagogical support to students, contributes to socialization and the formation of a general culture of the student's personality.

In modern conditions, extracurricular activities are designed to facilitate the implementation of the social (third) mission of the university, which is recognized as equivalent to educational and scientific missions, manifested in the social involvement of the university, the development of social partnership, the 'service to society'. In this regard, the development of volunteering as a form of extracurricular activities of students is realized. A number of regulatory documents, in particular the Program for Strategic Development of the RUDN University and the Program for the Development of Student Associations in the RUDN University, stimulate the development and implementation of socially-oriented volunteer projects. Increased attention both at the university level as a whole and at individual faculties is given to the development of the student mentoring (peer mentoring) system - the volunteering of senior students aimed at assisting underachieving students, supporting foreign students in the process of socio-cultural adaptation, their incorporation into the university life.

At the same time, the results of the survey show that volunteering is not a priority from the view point of the majority of respondents (see Table 2). During the discussion of this problem in focus groups, bachelor, master and postgraduate students agreed that volunteering is an important activity; 28 participants out of 30 shared the view that volunteers acquire valuable social experience, develop communication skills, leadership skills, initiative, and so on. However, the majority of focus group students (24 out of 30 ) are willing to engage in volunteer activity, provided its encouragement from the university administration and faculty members. Certificates of honor and diplomas, as well as additional points on the subjects studied were named as examples of encouragement.

In turn, the faculty members who participated in the focus group stressed the educational potential of volunteer activity, its resources for the development of social activity, responsibility and civic position of young people, but noted the low interest of most students in this type of activity. The reasons, from the point of view of teachers, lie both in the lack of free time, and in the pronounced individualism of the modern generation of students who are not ready for systematic voluntary, gratuitous work for the benefit of society.

During the discussion, the participants came to the conclusion that the development of volunteering as a kind of extracurricular activity at the university is possible when consolidating the efforts of all concerned, support and targeted assistance of socially-oriented volunteer activities of students from the administration and faculty members, consideration of the age and personality characteristics of modern students, in particular, features of their need-motivational sphere.

Proceeding from the data obtained in the course of the study, the authors developed a model for organizing extracurricular activities at the department, which is a complex, open system that reflects the goal, stages, and the predicted result (Figure 3). The mandatory stages preceding the planning of extracurricular activities should be: 1 ) diagnostic, involving the study and analysis of the opinions of students and faculty members; 2) goal-oriented and motivational, which assumes not only the concretization of the common goal and the formulation of tasks of extracurricular activities specific to the department, but also the formation of motivation for the participation of students and fellow teachers in it.

The data and conclusions obtained as a result of the research are important not only for one university, as they are comparable with the results of previous studies in other regions of the Russian Federation (Belikova, 2002). 


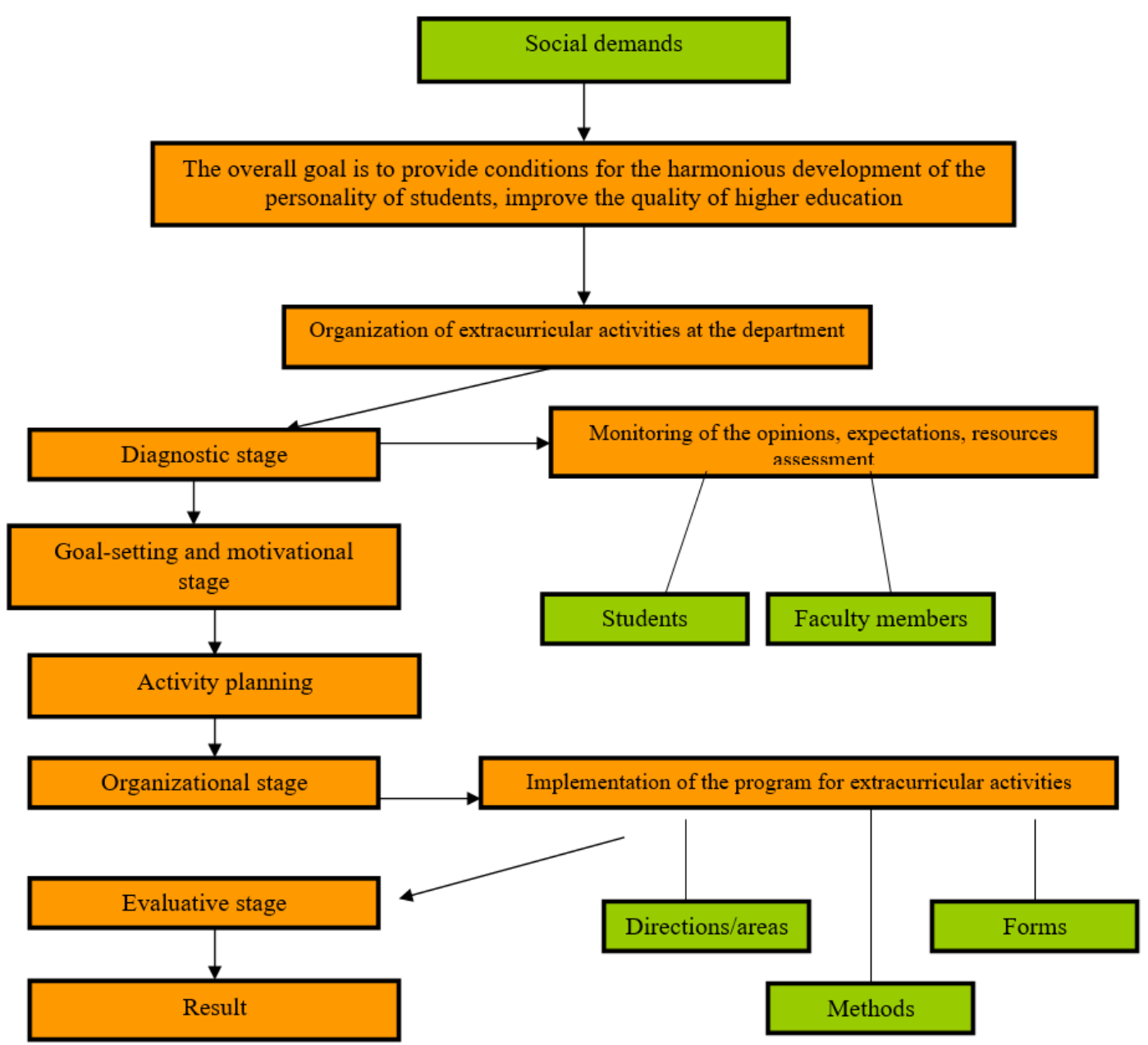

Figure 3. Model for arranging extracurricular activities with students by the chair (in the department)

\section{CONCLUSION}

Extracurricular activities are an integral part of the educational process at a modern university, providing conditions for the harmonious development of students' personality and improving the quality of professional training. Extracurricular activities are an independent function of higher education and represent a set of interrelated but different types of activities aimed at the all-round development of the student's personality and the formation of professional qualities of the future specialist.

The modernization of its tasks, content, forms, taking into account the modern requirements for training a specialist, on the one hand, and the views of all concerned (primarily students), on the other, are one of the key factors determining the effectiveness of the implementation of extracurricular activities.

The conducted research shows that there are some contradictions between the official tasks of extracurricular activities proclaimed at the university level and the needs of the modern generation of students. In particular, it is a contradiction between the relevance of socially-oriented volunteering and the low level of demand for this type of activity in the student environment. The existing contradictions make it necessary to monitor students' opinions and create conditions for the formation and development of their motivation to participate not only in mass cultural and career guidance events, but also in cultural- educational, socially significant and other types of activities.

The research findings allow for conclusion that the priority line of extracurricular activities at the departments should be professional upbringing and professional orientation of students.

The problems identified in the process of research require more in-depth study and comprehension in modern conditions. It is relevant to search for a flexible, adaptive model of extracurricular activities, taking into account the specifics of the educational environment of a particular institution.

From our point of view, it will be very promising to carry out studies that will enable to clarify the content, forms, and methods of extracurricular activities with regard to the opinions of ethnically/culturally diverse 
contingent of modern students, and to reveal potential of extracurricular activities in the adaptation of foreign students.

The research results are of pedagogical and university management interest. Assessing views and expectations of both faculty members and students may help university administration raise the effectiveness of extracurricular activities and strengthen their positive impact on students' personal and professional development.

\section{REFERENCES}

Alieva, L. V., Nefedova, N. A., \& Rudenko, I. V. (2014). Theoretical bases and principles of extracurricular activities as an innovative unit of the university educational system. Moscow: International Independent Ecological and Political University Press. (in Russian)

Bakoban, R. A., \& Aljarallah S. A. (2015). Extracurricular activities and their effect on the student's grade point average: Statistical study. Educational Research and Reviews, 10(20), 2737-2744. doi:10.5897/ERR2015.2436

Bartkus, K. R., Nemelka, B., Nemelka, M., \& Gardner, Ph. (2012). Clarifying the Meaning of Extracurricular Activity: A Literature Review of Definitions. American Journal of Business Education, 5(6), 693-703. doi:10.19030/ajbe.v5i6.7391

Belikova, L. F. (2002). Students' attitudes toward extracurricular activity in an institution of higher learning. Russian Education and Society, 44(2), 73-85. (in Russian)

Cheng, D. X., \& Zhao, Ch. M. (2006). Cultivating Multi-cultural Competence through Active Participation: Extracurricular Activities and Multi-cultural Learning. NASPA Journal, 43(4), 13-38. EJ751049

Clark, G., Marsden, R., Whyatt, J. D., Thompson, L., \& Walker, M. (2015). “It's Everything Else You Do...”: Alumni Views on Extracurricular Activities and Employability. Active Learning in Higher Education, 16(2), 133-147. doi:10.1177/1469787415574050

Gismatullina, E. K. (2012). Competitiveness of extra-curricular activities of students of university. Bulletin of NSU. Series: Social and Economics Sciences, 12(1), 127-138. (in Russian)

Gismatullina, E. K. (2013). Extracurricular activities of the higher educational institution as the factor of formation of social capital. Moscow: Moscow State University of Economics, Statistics and Informatics Press. (in Russian)

Hoffman, J. L. (2002). The impact of student co-curricular involvement on student success: Racial and religious differences. Journal of College Student Development, 43(5), 712-739. EJ653333

Logvinova, O. K. (2016). Multi-cultural education in the modern university: socio-pedagogical approach. The world of science, culture and education, 2(57), 161-164. (in Russian)

Mandel, B. R. (2014). Mentoring in the modern university: search for the solution of problems. Pedagogy, 8, 25-31. (in Russian)

Musaev, K. M. (2014). Formation of tolerance of the students of pedagogical college through extracurricular activities. Makhachkala: Dagestan State Pedagogical University Press. (in Russian)

Rudenko, I. V., \& Alieva, L. V. (2011). Extracurricular activities of the modern higher educational institution as the field of student's personality development. Bulletin of the Humanitarian Institute TSU, 3, 7-9. (in Russian)

Shakirova, E. F. (2008). The comparison of students' social activity characteristics in the college of education. Psychological science and education, 5, 26-35. (in Russian)

Strapp, C. M., \& Farr, R. J. (2010). To Get Involved or Not: The Relation Among Extracurricular Involvement, Satisfaction, and Academic Achievement. Teaching of Psychology, 37(1), 50-54. doi:10.1080/00986280903425870

Vintin, I. A. (2006). Pedagogical fundamentals of the social self-determination of students in the extracurricular activities in the higher educational institutions. Saransk the University of Mordovia Press. (in Russian)

Volkova, N. N. (2002). The system of professional education in the extracurricular activities. Secondary Vocational Education, 4, 50-53. (in Russian)

Zacherman, A., \& Foubert, J. (2014). The Relationship Between Engagement in Cocurricular Activities and Academic Performance: Exploring Gender Differences. Journal of Student Affairs Research and Practice, 51(2), 157-169. doi:10.1515/jsarp-2014-0016

\section{http://www.ejmste.com}

